GOMES, A.M.A.; MARIANO, R.L.R.; SILVEIRA, E.B.; MESQUITA, J.C.P. Isolamento, seleção de bactérias e efeito da utilização de Bacillus spp. na produção de mudas orgânicas de alface. Horticultura Brasileira, Brasília, v. 21, n. 4, p. 699-703, outubro-dezembro 2003.

\title{
Isolamento, seleção de bactérias e efeito de Bacillus spp. na produção de mudas orgânicas de alface ${ }^{1}$
}

\author{
Andréa M.A. Gomes ${ }^{1 * *}$; Rosa L.R. Mariano ${ }^{1^{* * * *}}$; Elineide B. Silveira ${ }^{2}$; Júlio C.P. Mesquita ${ }^{3}$ \\ UFRPE, ${ }^{1}$ Depto. agronomia, Área fitossanidade; ${ }^{2}$ Depto biologia, Área microbiologia, 52171-900 Recife-PE; ${ }^{3}$ Engenheiro Agrônomo, \\ Chã Grande-PE; **Bolsista Projeto Nordeste, CAPES/FACEPE; ***Bolsista CNPq; E-mail: andreamagomes@hotmail.com
}

\section{RESUMO}

Isolados bacterianos epifíticos e endofíticos, obtidos de plantas sadias de alface, foram avaliados para promoção de crescimento de mudas e plantas, respectivamente em estufa e campo de cultivo orgânico (Chã Grande-PE). Nos experimentos em estufa, foi utilizada a cultivar Verônica e em campo, as cultivares Verdinha e Verônica. Os isolados foram aplicados por bacterização simultânea nas sementes e substrato. Em campo, foram utilizados os isolados mais eficientes, C25 (Bacillus thuringiensis subvar. kenyae) e C116 (Bacillus pumilus), separadamente e em mistura, após teste de compatibilidade. Em estufa, foram avaliadas a matéria fresca de raízes (MFR), da parte aérea (MFPA) e total (MFT), 21 dias após a bacterização. Em campo, foi determinado o peso da matéria fresca total de plantas comercializáveis 21 e 28 dias após o transplante, respectivamente para as cultivares Verdinha e Verônica. Os mecanismos de ação de BPCP analisados foram produção de ácido indol acético, ácido cianídrico, solubilização de fosfatos e alterações dos teores foliares dos macronutrientes, N, P, K, Ca e Mg. Em estufa, as mudas apresentaram aumento significativo em relação à testemunha para MFR, MFPA e MFT quando foi utilizado o isolado C116 e para MFR e MFT utilizando-se o C25. No campo, não houve promoção significativa no crescimento nas plantas das cultivares Verdinha e Verônica, tratadas com C25 e C116 separadamente ou em mistura. Dos mecanismos de ação analisados verificou-se apenas elevação significativa $(\mathrm{P}=0,05)$ do teor foliar de $\mathrm{N}$ pelo isolado $\mathrm{C} 25$.

Palavras-chave: Lactuca sativa, Bacillus pumilus, Bacillus thuringiensis subvar. kenyae, bactérias promotoras de crescimento de plantas, mecanismos de ação, sistema orgânico.

\section{ABSTRACT}

Isolation, selection of bacteria, and effect of Bacillus spp. in the production of organic lettuce seedlings

Epiphytic and endophytic bacterial strains isolated from healthy lettuce plants were evaluated for growth promotion of seedlings and plants respectively under greenhouse and field conditions of organic production of lettuce, in Brazil. The cultivar Verônica was utilized in the greenhouse experiments and cvs. Verônica and Verdinha were evaluated in the field. The strains were applied by simultaneous bacterization of seed and substrate. In the field the most efficient strains $\mathrm{C} 25$ (Bacillus thuringiensis subvar. kenyae) and C116 (Bacillus pumilus) were utilized separated and in mixture after the compatibility assay. In greenhouse root fresh weight (MFR), shoot fresh weight (MFPA) and total fresh weight (MFT) were evaluated 21 days after bacterization. In field the total fresh weight of commercial plants was determined 21 and 28 days after transplant, respectively for cvs. Verdinha and Verônica. The mechanisms of BPCP studied were production of indolacetic acid, cyanidric acid, phosphate solubilization and alterations of $\mathrm{N}, \mathrm{P}, \mathrm{K}, \mathrm{Ca}$ and $\mathrm{Mg}$ foliar levels. In the greenhouse, seedlings treated with $\mathrm{C} 116$ showed significant increase in relation to controls for MFR, MFPA and MFT as well as those treated with C25 for MFR and MFT. In the field cvs. Verdinha and Verônica treated with $\mathrm{C} 25, \mathrm{C} 116$ or mixture did not significantly differ from control. None of the analyzed mechanisms were positive but strain C25 significantly increased the level of foliar $\mathrm{N}$.

Keywords: Lactuca sativa, Bacillus pumilus, Bacillus thuringiensis subvar. kenyae, plant growth-promoting bacteria, mechanisms, organic system.

\section{(Recebido para publicação em 12 de fevereiro de 2003 e aceito em 13 de agosto de 2003)}

A agricultura orgânica é uma das ati vidades agrícolas que mais se desenvolve em todo o mundo (Harkaly, 1998). Neste setor, a produção de hortaliças é atualmente a atividade mais praticada no Brasil, onde o mercado para produtos orgânicos vem crescendo $10 \%$ ao ano, desde 1990 (Penteado, 2000).

Nos últimos anos, o cultivo orgânico de alface (Lactuca sativa L.) tem se destacado em Pernambuco, principalmente, na Zona da Mata e Agreste, sendo a comercialização realizada em su- permercados e feiras de produtos orgânicos no Recife.

O uso de bactérias promotoras de crescimento de plantas (BPCP) impacta a produção agrícola, pelo aumento de rendimento (Kloepper et al., 1989). As BPCP atuam indiretamente pela supressão de doenças e diretamente pela produção ou alteração da concentração de fitohormônios, fixação de $\mathrm{N}$, pela solubilização de fosfatos minerais ou outros nutrientes do solo; oxidação do $\mathrm{S}$; aumento de permeabilidade das raízes e; produção de sideróforos (Cattelan, 1999; Mariano \& Kloepper, 2000). Destacam-se os gêneros Pseudomonas (Germida \& Freitas, 1994) e Bacillus (Turner \& Backman, 1991; Lazarovits $\&$ Nowak, 1997), sendo este último produtor de endosporos que sobrevivem por longos períodos no solo e em armazenamento (Lazarovits \& Nowak, 1997).

Apesar do número significativo de pesquisas sobre a utilização de BPCP na agricultura, poucas relatam a eficiência

1 Parte da tese de doutorado em Fitopatologia do primeiro autor, apresentada à UFRPE. 
dessas bactérias em alface (Rodríguez \& Fraga, 1999; Chabot et al., 1996). No presente trabalho, bactérias foram isoladas e avaliadas na produção orgânica de mudas e plantas de alface em estufa e campo, respectivamente. Foram ainda analisados os mecanismos de ação dessas bactérias.

\section{MATERIAL E MÉTODOS}

Os experimentos foram conduzidos no Laboratório de Fitobacteriologia da UFRPE, e em estufa e campo de cultivo orgânico, localizados no município de Chã Grande, região Agreste de Pernambuco, de maio de 2000 a julho de 2001.

Isolamento de bactérias endofíticas e epifíticas de plantas de alface

Sementes, raízes, caules e folhas de alface sadias, foram coletados em plantios comerciais de Chã Grande, para isolamento de bactérias epifíticas (Mariano et al., 2000) e endofíticas (Souza et al., 2000).

Seleção de bactérias promotoras de crescimento de mudas de alface

Foram realizados dois experimentos para seleção de bactérias promotoras de crescimento de mudas de alface em estufa. No primeiro, foram preparadas suspensões bacterianas a partir de 50 isolados epifíticos e 30 endofíticos com 36 horas de cultivo, em solução de $\mathrm{MgSO}_{4} \quad 0,1 \quad \mathrm{M}$ e ajustadas em fotocolorímetro $\left(\mathrm{A}_{580}=0,7\right)$. Utilizou-se o método da bacterização simultânea de sementes e substrato, que consistiu na deposição de $5 \mathrm{ml}$ da suspensão sobre cada semente ('Verônica') contida na superfície do substrato [organo-vegetal Plantmax ${ }^{\circledR}+$ húmus de minhoca $\left.(1: 1)\right]$ em cada célula de bandeja de poliestireno. A testemunha foi tratada apenas com a solução de $\mathrm{MgSO}_{4} 0,1 \mathrm{M}$. As bandejas foram mantidas durante 21 dias em estufa de produção de mudas orgânicas. Após esse período, avaliouse a matéria fresca de raízes (MFR), parte aérea (MFPA) e total (MFT). O delineamento experimental foi inteiramente casualizado, com cinco repetições, sendo a unidade experimental representada por duas plantas.
O segundo experimento foi realizado com os isolados bacterianos epifíticos (AL-12, AL-28 e AL-76) e endofíticos (AL-65 e AL-106) que apresentaram os melhores resultados na primeira seleção e mais 10 isolados epifíticos, previamente comprovados como BPCP em outras culturas, provenientes da coleção do Laboratório de Fitobacteriologia (C11, C21, C22, C25, C116, C210, C240, RAB7, RAB9 e R14). O método de bacterização e as variáveis mensuradas foram os mesmos descritos anteriormente. O delineamento experimental foi inteiramente casualizado, com quatro repetições, sendo a unidade experimental representada por 10 plantas.

Efeito de Bacillus thuringiensis subvar. kenyae e Bacillus pumilus, separadamente ou em mistura, na produção de alface em cultivo orgânico

Foi verificada a compatibilidade entre os isolados C25 e C116 em laboratório, pelo método de antibiose bactéria x bactéria (Mariano et al., 2000). O delineamento experimental foi inteiramente casualizado com quatro repetições, sendo a unidade experimental representada por uma placa de Petri.

Para o experimento de campo, foram preparadas suspensões dos isolados C25 e C116, separadamente e em mistura, na proporção de 1:1 (v:v). Sementes das cultivares Verdinha (grupo Lisa) e Verônica (grupo Crespa) foram bacterizadas conforme já descrito e as mudas permaneceram em estufa por 21 dias, sendo levadas para campo em 12/ $06 / 01$. Utilizou-se a mesma tecnologia empregada no cultivo orgânico pelos agricultores da região, consistindo de ausência de insumos químicos desde a sementeira até a colheita; adubação de fundação e de cobertura com, respectivamente, composto orgânico e torta de mamona; irrigação por gotejamento; capinas manuais dentro do canteiro com preservação de ervas daninhas entre canteiros; consórcio de cultivares diferentes em um mesmo canteiro e de espécies olerícolas diferentes entre canteiros. A avaliação foi realizada 21 e 28 dias após o transplante, época de colheita das cultivares Verdinha e Verônica, respectivamente, pelo peso da matéria fresca das plantas comercializáveis. A partir dos dados obtidos, calculou-se o índice de aumento (IA), utilizando-se a fórmula IA $(\%)=[(\mathrm{Tr}-$ Test $) /$ Test $] \mathrm{x}$ 100, onde: $\operatorname{Tr}=$ Tratamento $\mathrm{e}$ Test=Testemunha. $\mathrm{O}$ delineamento experimental foi em blocos casualizados, com quatro repetições, sendo que cada parcela útil $(4,00 \times 1,00 \mathrm{~m})$ constou de quatro fileiras com 12 plantas, totalizando 48 plantas para cada cultivar. $\mathrm{O}$ espaçamento usado foi $0,25 \mathrm{~m}$ entre plantas e fileiras.

Mecanismos de ação de Bacillus thuringiensis subvar. kenyae e Bacillus pumilus como promotores de crescimento de mudas de alface

Os isolados bacterianos $\mathrm{C} 25$ e $\mathrm{C} 116$ foram estudados quanto à produção de ácido cianídrico $(\mathrm{HCN})$ (Mariano et al., 2000), ácido indol acético (AIA) e solubilização de fosfato, ambos adaptados por Cattelan (1999). Como padrões positivos foram utilizados, respectivamente, Burkholderia cepacia GN1201, Chryseobacterium (Flavobacterium) indologenes GW2103 e Pseudomonas chlororaphis GN1212, cedidos pelo Dr. Catellan da Embrapa Soja. O delineamento experimental foi inteiramente casualizado com quatro repetições, sendo a unidade experimental representada por uma placa de Petri.

Os isolados C25 e C116 também foram avaliados quanto à indução de alterações nos teores foliares de N, P, $\mathrm{K}, \mathrm{Ca}$ e $\mathrm{Mg}$ em $\mathrm{g} \mathrm{kg}^{-1}$. Sementes da cultivar Verônica foram bacterizadas conforme já descrito e analisadas 21 dias após o semeio. O delineamento experimental foi inteiramente casualizado com quatro repetições, sendo a unidade experimental representada por 10 mudas. Foram utilizados os métodos de Kjeldahl para $\mathrm{N}$, colorimétrico do molibdo-vanadato de amônio para $\mathrm{P}$, fotometria de chamas para $\mathrm{K}$ e espectrofotometria de absorção atômica para Ca e Mg (Bezerra Neto et al., 1994; Sarruge \& Haag, 1974).

\section{Análise estatística}

Os dados foram submetidos à análise de variância, sendo as médias comparadas pelo teste de agrupamento Scott-Knott $(\mathrm{P}=0,05)$ no primeiro experimento e, pelo teste de Duncan $(\mathrm{P}=0,05)$ nos demais. 
Tabela 1. Crescimento de mudas de alface cultivar Verônica bacterizadas com isolados epifíticos e endofíticos, avaliadas após 21 dias, em estufa. Chã Grande (PE), UFRPE, 2001.

\begin{tabular}{llccc}
\hline \multicolumn{1}{c}{ Tratamento } & \multicolumn{1}{c}{ Identificação } & MFR $\mathbf{( m g )})^{1 /}$ & MFPA $\mathbf{( m g )}$ & MFT (mg) \\
\hline C116 & Bacillus pumilus & $138,53 \mathrm{a}^{3 /}$ & $240,39 \mathrm{a}$ & $378,92 \mathrm{a}$ \\
C25 & Bacillus thuringiensis subvar. kenyae & $135,25 \mathrm{a}$ & $224,73 \mathrm{ab}$ & $359,98 \mathrm{a}$ \\
C22 & Bacillus sp. & $122,68 \mathrm{ab}$ & $223,46 \mathrm{ab}$ & $346,14 \mathrm{ab}$ \\
C11 & Bacillus sp. & $111,61 \mathrm{ab}$ & $217,28 \mathrm{ab}$ & $328,87 \mathrm{ab}$ \\
R14 & Bacillus subtilis & $124,15 \mathrm{ab}$ & $216,73 \mathrm{ab}$ & $340,88 \mathrm{ab}$ \\
C240 & Bacillus cereus & $113,75 \mathrm{ab}$ & $214,47 \mathrm{ab}$ & $328,24 \mathrm{ab}$ \\
AL-76 & não identificado & $118,91 \mathrm{ab}$ & $208,54 \mathrm{ab}$ & $327,63 \mathrm{ab}$ \\
RAB7 & Bacillus megaterium & $108,80 \mathrm{ab}$ & $206,87 \mathrm{ab}$ & $315,68 \mathrm{ab}$ \\
C210 & Bacillus cereus & $109,61 \mathrm{ab}$ & $204,88 \mathrm{ab}$ & $314,49 \mathrm{ab}$ \\
AL-106 & não identificado & $123,72 \mathrm{ab}$ & $204,37 \mathrm{ab}$ & $328,10 \mathrm{ab}$ \\
C21 & Bacillus sp. & $109,28 \mathrm{ab}$ & $199,66 \mathrm{ab}$ & $308,94 \mathrm{ab}$ \\
AL-28 & não identificado & $109,61 \mathrm{ab}$ & $188,37 \mathrm{ab}$ & $297,98 \mathrm{abc}$ \\
RAB9 & Bacillus sp. & $97,00 \mathrm{ab}$ & $186,73 \mathrm{ab}$ & $283,73 \mathrm{abc}$ \\
AL-65 & não identificado & $108,37 \mathrm{ab}$ & $186,04 \mathrm{ab}$ & $294,43 \mathrm{abc}$ \\
AL-12 & não identificado & $88,46 \mathrm{~b}$ & $182,05 \mathrm{ab}$ & $206,56 \mathrm{c}$ \\
Testemunha & & $87,48 \mathrm{~b}$ & $164,78 \mathrm{~b}$ & $252,26 \mathrm{bc}$ \\
\hline C.V. (\%) & & 27,30 & 25,39 & 24,57 \\
\hline
\end{tabular}

${ }^{1 /} \mathrm{MFR}=$ matéria fresca raiz; MFPA= material fresca parte aérea; MFT= matéria fresca total;

${ }^{2 /}$ Isolados epifíticos (C11, C21, C22, C25, C116, C210, C240, RAB7, RAB9, R14, AL-12, AL-28 e AL-76) e endofíticos (AL-65 e AL-106).

${ }^{3 /}$ Médias seguidas da mesma letra nas colunas não diferem significativamente entre si ao nível de 5\% de probabilidade pelo teste de Duncan.

\section{RESULTADOS E DISCUSSÃO}

De plantas sadias de alface foram obtidos 114 isolados bacterianos, sendo 60 epifiticos $(56,13 \%)$ e 54 endofíticos $(43,87 \%)$. Sementes, raízes, caule e folhas originaram, respectivamente, 13,$16 ; 17,54 ; 1,75$ e $23,68 \%$ isolados epifíticos, além de 0,$88 ; 16,67 ; 10,53$ e $15,79 \%$ isolados endofíticos. Os isolados estão depositados na Coleção de Culturas do Laboratório de Fitobacteriologia da UFRPE. A população epifítica foi ligeiramente dominante em relação à endofífica, ambas encontradas em maior porcentagem em raízes e folhas.

Dos isolados obtidos, 80 foram testados para promoção de crescimento de mudas de alface em estufa. De acordo com McInroy \& Kloepper (1995), isolados bacterianos provenientes da comunidade endofítica e epifítica, podem ser potenciais agentes de controle biológico e de promoção de crescimento de plantas. Desses 80 , apenas três isolados epifíticos (AL-12, AL-28 e AL-76) e dois endofíticos (AL-65 e AL-106) diferiram significativamente da testemunha com relação às variáveis MFR, MFPA e MFT. Segundo Chen et al. (1996), seleções preliminares para BPCP utilizam grande número de isolados, principalmente porque menos de $1 \%$ são capazes de promover crescimento em plantas.

No segundo experimento (Tabela 1) a maioria dos 15 isolados bacterianos promoveu o desenvolvimento de mudas de alface cultivar Verônica, em relação às variáveis avaliadas. Contudo, apenas C116 (B. pumilus) e C25 (B. thuringiensis subvar. kenyae) diferiram significativamente da testemunha para MFR, MFPA e MFT (C116) e para MFR e MFT (C25), sem diferirem entre si.

Os isolados $\mathrm{C} 116$ e $\mathrm{C} 25$ são provenientes de couve, evidenciando que não há especificidades para um hospedeiro, sendo que facilmente podem colonizar hospedeiros de espécies diferentes, até mesmo com maior intensidade (QuadtHalmann \& Kloepper, 1996) e promovendo o crescimento (Mello et al., 2002). Estes autores observaram ausên- cia de especificidade dos isolados $\mathrm{C} 210$, ENF10, ENF16 e RAB9, obtidos de couve, feijão e rabanete, respectivamente, com relação à promoção de crescimento em mudas de abacaxizeiro micropropagadas.

O aumento de MFT em mudas de alface foi de 50,21 e 42,70\%, induzido respectivamente por $\mathrm{C} 116$ e C25. Estes resultados concordam com Silveira et al. (2001) que obtiveram em mudas de pepino bacterizadas com os isolados PEP81 (B. amyloliquefaciens) e PEP91 (Enterobacter cloacae) aumentos de, respectivamente, 33,3 e $27,5 \%$ para matéria seca total. Bio Yield ${ }^{\mathrm{TM}}$, produto contendo Bacillus amyloliquefaciens GB99 e Paenibacillus macerans GB122, induziu aumentos de MFT em mudas de tomate $(69,4 \%)$ e pimentão $(106 \%)$ (Bio Yield $^{\mathrm{TM}}$, 2000.) Portanto, os isolados C25 e C116 podem ser considerados promotores de crescimento, viabilizando a produção de mudas de alface mais vigorosas que possivelmente serão menos afetadas pelo estresse do transplante.

No teste de compatibilidade entre os isolados, C116 inibiu C25 mas não foi 
Tabela 2. Quantidade de macronutrientes em mudas de alface cultivar Verônica bacterizadas com Bacillus thuringiensis subvar. kenyae $\mathrm{C} 25$ e Bacillus pumilus C116, avaliadas após 21 dias em estufa. Chã Grande (PE), UFRPE, 2001.

\begin{tabular}{lccccc}
\hline \multirow{2}{*}{ Tratamento } & $\mathbf{5}$ & $\mathbf{P}$ & $\mathbf{K}$ & $\mathbf{C a}$ & $\mathbf{M g}$ \\
\cline { 2 - 6 } & $26,11^{2 /} \mathrm{a}$ & $6,99 \mathrm{a}$ & $33,28 \mathrm{~b}$ & $0,17 \mathrm{a}$ & $0,28 \mathrm{a}$ \\
C25 & $18,37 \mathrm{~b}$ & $6,88 \mathrm{a}$ & $29,50 \mathrm{~b}$ & $0,30 \mathrm{a}$ & $0,24 \mathrm{a}$ \\
C116 & $20,25 \mathrm{~b}$ & $7,05 \mathrm{a}$ & $41,69 \mathrm{a}$ & $0,10 \mathrm{a}$ & $0,21 \mathrm{a}$ \\
Testemunha & 12,78 & 8,72 & 12,99 & 65,13 & 77,51 \\
\hline C.V. (\%) & &
\end{tabular}

${ }^{1 /} \mathrm{N}=$ nitrogênio; $\mathrm{P}=$ fósforo; $\mathrm{K}=$ potássio; $\mathrm{Ca}=$ cálcio e $\mathrm{Mg}=$ magnésio

${ }^{2 /}$ Médias seguidas da mesma letra na coluna não diferem significativamente entre si ao nível de 5\% de probabilidade pelo teste de Duncan.

inibido por ele. Essa incompatibilidade in vitro não significa, necessariamente, incompatibilidade in vivo, podendo inclusive, aumentar a supressão de doenças (De Boer, 1999). Apesar da inibição in vitro do $\mathrm{C} 25$ pelo $\mathrm{C} 116$, não houve interação entre os dois isolados in vivo, com relação à promoção de crescimento das plantas no campo. Isolados coinoculados podem não influenciar um ao outro devido à separação espacial entre eles nas raízes, ou ainda porque a produção de compostos secundários inibitórios ocorre na fase estacionária e não atua nos estágios iniciais de colonização (Duffy et al., 1996).

No campo, C25 e C116, separadamente ou em mistura, não promoveram significativamente o crescimento de plantas de alface (dados não apresentados), embora tenham elevado o peso da matéria fresca de plantas comercializáveis das cultivares Verdinha $(19,49$ a $27,31 \%)$ e Verônica (15,39 a 21,91\%). Chabot et al. (1996) utilizando Rhizobium leguminosarum bv. phaseoli R1 e Serratia sp. 22 como solubilizadoras de fosfatos, obtiveram aumentos significativos $(\mathrm{P} \leq 0,10)$ de matéria seca da parte aérea de plantas comercializáveis de apenas 6 e 7\%, respectivamente. Apesar de Germida \& Freitas (1994) relatarem aumentos acima de $70 \%$ no peso da matéria fresca de plantas de alface, com $P$. aeruginosa R75, na China, onde as BPCP são utilizadas rotineiramente na agricultura, aumentos de rendimento de $15 \%$ são obtidos em hortaliças folhosas (Zhang et al., 1996).

No presente trabalho, observou-se que a promoção de crescimento das mudas prolongou-se até o campo com valores elevados, apesar de não signifi- cativos. Efeito similar porém significativo, foi observado pelo uso do Bio Yield $^{\mathrm{TM}}$ em tomate e pimentão (Bio Yield $\left.^{\mathrm{TM}}, 2000\right)$ salientando-se que houve grande variação $(5,2$ a 56,0\%) no aumento de produtividade em tomate, dependendo do local de realização dos experimentos.

Nas condições dos ensaios realizados in vitro, nenhum dos isolados produziu AIA, HCN ou solubilizou fosfato, como evidenciado nos padrões utilizados, sugerindo que esses mecanismos não foram responsáveis pela promoção de crescimento.

A bacterização de mudas de alface com o isolado C25 elevou significativamente $(\mathrm{P}=0,05)$ o teor foliar de $\mathrm{N}$ em relação à testemunha (Tabela 2 ). $\mathrm{O} \mathrm{N}$ favorece o crescimento vegetativo de hortaliças, e eleva a produtividade (Filgueira, 2000). A deficiência de $\mathrm{N}$ em alface retarda o crescimento da planta e induz ausência ou má formação da cabeça, entre outros sintomas (Katayama, 1993). Assim, a elevação dos teores de $\mathrm{N}$ pelo isolado $\mathrm{C} 25$ pode estimular o crescimento vegetativo de mudas de alface além de, prevenir a deficiência. Esta elevação pode ser explicada pelo aumento de vigor das plantas que absorveram maior quantidade deste nutriente (Dashti et al., 1997; Mello et al., 2002). Turner \& Backman (1991) relataram o aumento dos níveis de $\mathrm{N}$ em plantas de amendoim tratadas com $B$. subtilis como um dos mecanismos de ação deste isolado. Ainda segundo Pal et al. (2000), Pseudomonas fluorescens e Pseudomonas spp. aumentaram significativamente a biomassa de amendoim, elevando o $\mathrm{N}$ em 5-9\% e 6-12\%, respectivamente em plantas e amêndoas.
Os isolados C25 e C116, reduziram significativamente o teor de $\mathrm{K}$ em relação à testemunha. Dentre os mecanismos de ação das BPCP são citados fixação de N, solubilização de P, oxidação de $\mathrm{S}$ e disponibilização de Fe (Mariano \& Kloepper, 2000), sem contudo haver referências ao K. Uma possível explicação para a redução de $\mathrm{K}$ seria a inibição competitiva com outros nutrientes (Malavolta, 1980).

Neste estudo, demonstrou-se a potencialidade do uso dos isolados $\mathrm{C} 116$ de B. pumilus e C25 de B. thuringiensis subvar. kenyae, separadamente, na produção de mudas de alface no cultivo orgânico, com possível prolongamento de efeito sobre a produção. Novos testes devem ser realizados em estufa e campo, visando elevar a eficiência destes isolados no aumento da produtividade, antes dos estudos de formulação de um produto comercial.

\section{AGRADECIMENTOS}

Os autores agradecem a UFRPE e ao CNPq (Proc. 467.149/00-3) pelo financiamento que possibilitou a realização deste trabalho.

\section{LITERATURA CITADA}

BEZERRA NETO, E.; ANDRADE, A.G.; BARRETO, L.P. Análise química de tecidos $e$ produtos vegetais. Recife:UFRPE, 1994. 99 p.

BIO YIELD ${ }^{\mathrm{TM}}$ Transplanted vegetable and vine crops. Plano: GUSTAFSON, 2000. Disponível em: <http:www.helenachemical-west.com/data/ product $\% 20$ info /bioyieldmanual.pdf $>$ Acesso em 28 jan. 2003.

CATTELAN, A.J. Métodos qualitativos para determinação de características bioquímicas e fisiológicas associadas com bactérias promotoras de crescimento vegetal. Londrina: EMBRAPACNPS, 1999. 36 p. 
CHABOT, R.; ANTOUN, H.; CESCAS, M.P. Gowth promotion of maize and lettuce by phosphate-solubilizing Rhizobium leguminosarum biovar phaseoli. Plant Soil, v. 184, p. 311-321, 1996.

CHEN, Y.; MEI, R.; LIU, L.; KLOEPPER, J.W The use of yield increasing bacteria (YIB) as plant growth-promoting rhizobacteria in chinese agriculture. In: UTKHEDE, R.S.; GUPTA, V.K (Eds.) Management of soil born disease. Ludhiana: Kalyani Publishers, 1996. p. 165-184.

DASHTI, N.; ZHANG, F.; HYNES, R.; SMITH, D.L. Application of plant growth-promoting rhizobacteria to soybean (Glycine max [L.] Merr.) increases protein and dry matter yield under shortseason conditions. Plant and Soil, v. 188, p. 3341, 1997.

DE BOER, M.; VAN DER SLUIS, I.; VAN LOON, L.C.; BAKKER, P.A.H.M. Combining fluorescent Pseudomonas spp. strains to enhance suppression of fusarium wilt of radish. European Journal of Plant Pathology, v. 105, p. 201-210, 1999.

DUFFY, B.K.; SIMON, A.; WELLER, D.M. Combination of Trichoderma koningii with fluorescent pseudomonads for control of take-all on wheat. Phytopathology, v. 86, n. 2, p. 188-194, 1996.

FILGUEIRA, F.A.R. Novo manual de olericultura: agrotecnologia moderna na produção e comercialização de hortaliças 1. ed. Viçosa: Editora UFV, 2000. 402 p.

GERMIDA, J.J.; FREITAS, J.R. Growth promotion of cabbage, lettuce and onion by fluorescent pseudomonads under growth chamber conditions. In: WORKSHOP ON PLANT GROWTH-PROMOTING RHIZOBACTERIA, 3.,1994, Adelaide. Proceedings... Adelaide: OEDC-OEDC, 1994. p. 37-39.

HARKALY, A. Perspectivas da agricultura orgânica no mercado internacional. In: SOUZA, J.L.; CARMO C.A.S. (Coord.) I Encontro nacional sobre produção orgânica de hortaliças. Palestras e trabalhos técnicos. Vitória: EMCAPA, 1998. p. 57-66.
KATAYAMA, M. Nutrição e adubação de alface, chicória e almeirão. In: FERREIRA, M.E.; CASTELANE, P.D.; Da CRUZ, M.C.P. (Eds.) Nutrição e adubação de hortaliças. Piracicaba: Potafos, 1993. p. 141-148.

KLOEPPER, J.W.; LIFSHITZ, R.L.; ZABLOTOWICZ, R.M. Free-living bacterial inocula for enhancing crop productivity. Trends Biotechnology, v. 7, p. 39-44, 1989.

LAZAROVITS, G.; NOWAK, J. Rhizobacteria for improvement of plant growth and establishment. HortScience, v. 32, n. 2, p. 188-192, 1997.

MALAVOLTA, E. Os elementos minerais. In: MALAVOLTA, E. Elementos de nutrição mineral de plantas. São Paulo: Ceres, 1980. p. 104218.

MARIANO, R.L.R.; ASSIS, S.M.P.; SILVEIRA E.B.; GOMES, A.M.A. Mecanismos de ação de bactérias promotoras de crescimento. In MARIANO, R.L.R. (Coord.). Manual de práticas em fitobacteriologia. Recife: Editora Universitária, 2000. p. 139-151.

MARIANO, R.L.R.; KLOEPPER, J.W. Método alternativo de biocontrole: resistência sistêmica induzida por rizobactérias. Revisão Anual de Patologia de Plantas, v. 8, p. 121-137, 2000.

MCINROY, J.A.; KLOEPPER, J.W. A survey of indigenous bacterial endophytes from cotton and sweet corn. Plant and Soil, v. 173, p. 1-6, 1995.

MELLO, M.R.F.; MARIANO, R.L.R.; MENEZES, M.; CÂMARA, T.R.; ASSIS, S.M.P Seleção de bactérias e métodos de bacterização para promoção de crescimento em mudas de abacaxizeiro micropropagadas. Summa Phytopathologica, v. 28, n. 3, p. 222-228, 2002.

PAL, K.K.; BHAFF, D.M.; CHAUHAN, S.M. Plant growth promoting fluorescent pseudomonads enhanced peanut growth, yield and nutrient uptake. $1 n$ : INTERNATIONAL WORKSHOP ON PGPR. 5., 2000. Cordoba Proceedings... Cordoba: OECD, 2000, p. 90.

PENTEADO, S.R. Introdução à agricultura orgânica-normas e técnicas de cultivo. Campinas: Editora Grafinagem, 2000. 110 p.
QUADT-HALLMANN, A.; KLOEPPER, J.W. Immunological detection and localization of the cotton endophyte Enterobacter asburiae JM22 in different plant species. Canadian Journal of Microbiology, v. 42, p. 1144-1154, 1996.

RODRÍGUES, H.; FRAGA, R. Phosphate solubilizing bacteria and their role in plant growth promotion. Biotechnology Advances, v. 17, p. 319339, 1999.

SARRUGE, J.R.S.; HAAG, H.P. Análise químicas em plantas. Piracicaba: USP - ESALQ, 1974. $56 \mathrm{p}$.

SILVEIRA, E.B; SOUZA, J.R.B.S.; MARIANO, R.L.R. Efeito de bactérias na promoção de crescimento de plantas de pepino. Fitopatologia Brasileira, Brasília, v. 25, suplemento, p. 302, 2001.

SOUZA, J.R.B.S.; MEDEIROS, F.H.V. SILVEIRA, E.B.; GOMES, A.M.A.; VIANA, I.O. Avaliação de metodologias para isolamento de bactérias endofíticas. In: X CONGRESSO DE INICIAÇÃO CIENTÍFICA, 2000, Recife. Anais... Recife: UFRPE, 2000, p. 53-54.

TURNER, J.T.; BACKMAN, P.A. Factors relating to peanut yield increases after seed treatment with Bacillus subtilis. Plant Disease, v. 75, n. 4, p. $347-$ 353, 1991.

ZHANG, S.; XU, W.; YAN, Z.; MEI, R. Research and commercialization of yield-increasing bacteria (YIB) in China. In: INTERNATIONAL WORKSHOP ON BIOLOGICAL CONTROL OF PLANT DISEASES, 1., 1996, Beijing. Proceedings... Beijing: China Agricultural University Press, 1996. p. 47-53. 